\title{
A COMPARISON OF TURKISH ACCOUNTING STANDARDS-16 AND TURKISH TAX LAW FOR DISPOSAL OF TANGIBLE FIXED ASSETS
}

DOI: 10.17261/Pressacademia.2020.1256

PAP- V.11-2020(28)-p.145-149

Ozge Ergul ${ }^{1}$, Suat Teker ${ }^{2}$

${ }^{1}$ Isik University, Institute of Social Sciences, Istanbul, Turkey. ozgergl|@gmail.com.tr, ORCID: 0000-0000-0000-0000

${ }^{2}$ Isik University, İnstitute Of Social Sciences, Istanbul, Turkey. suat.teker@isikun.edu.tr, ORCID: 0000-0002-7981-3121

To cite this document

Ergul, O., Teker, S.. (2020). A Comparison of Turkish Accounting Standards-16 and Turkish Tax Law for disposal of tangible fixed assets. PressAcademia Procedia (PAP), V.11, p.145-149.

Permemant link to this document: http://doi.org/10.17261/Pressacademia.2020.1256

Copyright: Published by PressAcademia and limited licenced re-use rights only.

\begin{abstract}
Purpose- In the globalized world economy, it has become critically important for companies to form a common language to convey the company values to the financial markets. Establishing a common language in the field of accounting, the companies adopted common standards and started to apply. In this respect, our country has entered into the process of adapting to the standards that are the global language of accounting. The issue of compliance with standards is an important phenomenon for the European Union process.

Methodolgy- Tangible assets constitute a weighted part of the financial statements for real sector companies comparint to the service and commercial companies. The calculations of acquisition costs, accurately reflecting these costs to the financial statements and moving rhese assets off the balance sheet are important information for users. This study has a comparetive approach to investigate the treatment of tangible assets unders different Turkish accounting standards.

Findings- The disposal of tangible assets under the provisions of Turkish Accounting Standards-16 and the Turkish Tax Legislation is treated diffrently. There are a number of similarities and differences in accounting recordings and disposals of tangible fixed using the underlying standards.

Conclusion- The accounting treatment for recordings and diposals of tangible assets are examined under different Turkish accounting standards. A number of public real sector companies are examined about their treatment to tangible assets.
\end{abstract}

Keywords: Tangible fixed assets, Tax Procedure Law, long term assets, Turkish Accounting Standards.

JEL Codes: M40, M41, M48

\section{ELDEN ÇIKARILAN MADDI DURAN VARLIKLARIN TMS-16 VE VUK AÇISINDAN KARŞILAŞTIRMASI}

\section{ÖZET}

Amaç- Küreselleşen dünya ekonomisinde şirketlerin ortak bir dil oluşturabilmesi ve şirket değerlerinde anlaşılabilir olmak önem kazanmıştır. Ortak dil oluşturulabilmesi muhasebe alanında, şirketler tarafından ortak standartlar benimsenerek uygulanmaya başlanmıştır. Ülkemiz tarafından bu hususta muhasebenin küresel dili olan standartlara uyum sağlama sürecine girilmiş ve uygulamalar a geçilmiştir, muhasebe standartlarına uyum sağlama konusu Avrupa Birliği süreci açısından önemli bir olgudur.

Yöntem- Özellikle hizmet ve ticaret sektörü dışnda kalan üretim işletmeleri gibi işletmelerin finansal tablolarında önemli bir kısmı oluşturan maddi duran varıklar kalemlerine ilişkin uygulamalar, maddi duran varlıklara ait gerçekleştirilecek maliyet hesaplamalarının doğru bir şekilde tablolara yansıtılması, maddi duran varıkların hangi şekilde bilanço dışı bırakılabileceği, bilanço dışı bırakılmasında kullanılan muhasebe hesapları ve kayıt düzenleri, bu işlemlerin finansal tablolara hangi şekilde yansıtılacağı konusu, finansal tablo kullanııılarının talep ettiği bilgi ihtiyacı ile uyumlu olarak düzenlemesi yönünden önemli hususlardır. Bu çalışmada, maddi duran varlıklar konusunu kapsayan muhasebe standartları karşılaştırmalı olarak incelenmiş ve gerçek firmaların bu konu ile ilgili uygulamaları analiz edilmiştir.

Bulgular- Maddi duran varlıkların elden çıkarılması konusunda, Türkiye Muhasebe Standartları 16 ve Türk vergi mevzuatında yer alan hükümler karşılaştırıldığında; elden çıkarılan maddi duran varlıkların hangi şekilde bilanço dışı bırakılacağı konusunda benzerlik ve farklııkların olduğu görülmektedir.

Sonuç- Çalışmanın kapsamında maddi duran varlık konusu kısmen ele alınmış olup, elden çıkarılan maddi duran varlıklara ilişkin var olan mevcut uygulamalar üzerinde ağırlıklı olarak durulmuş ve uygulamaya yansıyan sonuçları incelenmiştir.

Anahtar Kelimeler: Maddi duran varlıklar, Vergi Usul Kanunu, duran varlıklar, Türk Vergi Sistemi, Türkiye Muhasebe Standartları. JEL Kodları: M40, M41, M48. 


\section{Gíriş}

Bu çalışma içeriğinde Türkiye Muhasebe Standartları hükümleri ile Vergi Usul Kanunu hükümlerinde belirtilen maddi duran varlığa ilişkin kavramlar anlatılııs, elden çıkarılan maddi duran varlığa ait uygulamalar Maddi Duran Varlık Standardı 16 ve Vergi Usul Kanunu çerçevelerinde değerlendirilerek karşılaştırımışır.

Bu çalışmada amaç, finansal tablolarda yer verilen maddi duran varlık hesaplarının incelenmesi, maddi duran varlıkların elden çıkarılması durumunda Türk Vergi Kanunları ile Maddi Duran Varlık Standardındaki uygulama farklılıklarını, finansal tablolara yansılamalarıve her iki uygulamaya yönelik eleştiriler, önerilerde bulunulmasıdır.

Muhasebenin kavram ve tanımlamalarına, muhasebe standartlarının çeşitli tanımlamalarına yer verilmiş olup Vergi Usul Kanunu genel itibarıyla tanımlanmaya çalışılmıştır. Çalışmada bu bölümde ayrıca finansal tablo kullanıcılarına önemli bilgiler veren maddi duran varlıklara ait Maddi Duran Varlık Standardı ile Türk Vergi Sisteminde yer alan tanımlamalar yapılmış, önemleri açıklanmıştır.

Çalışmada elden çıkarılan maddi duran varlık kavramları Türk Vergi Sistemi ile Maddi Duran Varlık Standardınca incelenmiş, her iki uygulamadaki düzenlemelere yer verilerek, uygulamaların karşılaştırmaları yapılarak, her iki uygulamaya ilişkin varsayımsal örneklere yer verilmiş, bu örneklere ilişkin karşılaştırma tablosu ile uygulamalar arasındaki benzerlik ve farklııklar açıklanmaya çalışılmıştır.

Çalışmanın devamında, bazı halka açık şirketlerin Türkiye Muhasebe Standarları gereğince hazırladıkları finansal tablo ve dipnotlardan çıkarımlar yapılarak elden çıkarılan maddi duran varlıkların finansal tablolara yansımaları üzerinde incelemeler yapılmış ve durum analiz edilerek incelenmiştir.

\section{MUHASEBE STANDARTLARI VE VERGI USUL KANUNU'NDA MADDI DURAN VARLIK KAVRAMINA ILIŞKIN GENEL BILGILER}

Maddi Duran Varlık Standardı́nın 6'ncı paragrafında, direkt olarak "maddi duran varlık" tanımına yer verilmiştir. Tanımda maddi duran varlıklar, kullanımı bir dönemden daha uzun olarak öngörülmüş olan, hizmet ya da mal üretimi ya da arzında kullanılması, işletme tarafından başka kişi veya kurumlara kiralanması ya da idari gayeler çerçevesinde kullanılmak üzere bilançoda tutulan fiziki varlıklar şekilde yer almaktadır. Bununla birlikte, standardın “Muhasebeleştirme sonrası ölçüm” bölümünün 37'nci paragrafında örnek teşkil etmesi açısından maddi duran varlık çeşitleri sayılmıştır. Söz konusu paragrafta işletme faaliyet konularında benzer nitelik ile kullanım amacına sahip olan varlıkların gruplandırımasının her bir maddi duran varlık sınıflamasını oluşturacağı hususu belirtilmekle beraber yer verilen maddi duran varlık örneklerinin farklı MDV sınıflarını oluşturacağı belirtilmiştir. TMS 16 gereğince farklı maddi duran varlık sınıfına a it duran varlık örnekleri Arazi, Arazi ve Binalar, Makinalar, Gemiler, Uçaklar, Motorlu Taşıtlar, Mobilya ve Demirbaşlar, Ofis Gereçleri, Taşıyııı Bitkiler bulunmaktadır.

Muhasebe Sistemi Uygulama Genel Tebliği'nde duran varlık kavramı bir sene süre zarfında veya hesap dönemi süresinden daha fazla süre zarfında işletmenin faaliyetlerinin sürdürülmesi amacıyla aktifte yer alan, bir seneden önce ya da normal hesap dönemi içerisinde nakde çevrilmesi ya da tüketimi öngörülmeyen iktisadi kıymetler şeklinde tanımlanmış olup, ana hesap grubu duran varlıklar olan maddi duran varlıklara ilişkin tanımlamalara da bu düzenlemede yer verilmiştir. Demirbaşlar, binalar, yer altı ve yer üstü düzenleri, arazi ve arsalar, yapılmakta olan yatırımlar, verilen avanslar, tesis makine ve cihazlar, diğer maddi duran varlıklar, taşıtlar maddi duran varlıklar hesap grubunda bulunmakta olup, tek düzen hesap planı kapsamında yer almaktadırlar.

Tablo 1: Maddi Duran Varlıklar Kavramı, Kapsamı, Sınıflandırılmasının TMS 16 ve VUK Açısından Karşılaştırması

\begin{tabular}{|c|c|c|}
\hline Karşılaştırma Kıstası & Türkiye Muhasebe Standardı 16 & Vergi Usul Kanunu \\
\hline MDV Tanımı & TMS- 16 da mevcuttur. & $\begin{array}{l}\text { Direkt Vergi Usul Kanunu maddelerinde } \\
\text { bulunmamaktadır. MSUGT'de detaylı olarak } \\
\text { tanımlanmıştır. }\end{array}$ \\
\hline $\begin{array}{l}\text { MDV Tanımlama } \\
\text { Uyumları }\end{array}$ & $\begin{array}{l}\text { Mevcuttur. Bu tanımlar, MSUGT'de yer alan } \\
\text { tanımlar ile de uyumlu olduğu görülmektedir. }\end{array}$ & $\begin{array}{l}\text { Fakat MSUGT' de yer alan tanım TMS } 16 \text { ile } \\
\text { uyumlu olduğu görülmektedir. }\end{array}$ \\
\hline $\begin{array}{l}\text { Maddi Duran } \\
\text { Varlıkların } \\
\text { Sınıflandırılması }\end{array}$ & $\begin{array}{l}\text { TMS } 16 \text { paragraf } 37^{\prime} \text { de işletme iştigal konularında } \\
\text { benzer kullanımı olan ve benzer nitelikteki maddi } \\
\text { duran varlıkların MDV sınıfını oluştutacağı } \\
\text { belirtilmekle birlikte ayrı sınılarda yer alan duran } \\
\text { varlıklardan örneklere yer verilmiştir. Genel } \\
\text { itibarıyla bir sınıflama yer almamaktadır. Örnek } \\
\text { sınıflamalar MSUGT'de yer alan hesap grupları ile } \\
\text { uyumludur. }\end{array}$ & $\begin{array}{l}\text { MSUGT'de sınıflandırma genel hatları itibarıyla } \\
\text { hesap adı bazında yer almaktadır. }\end{array}$ \\
\hline $\begin{array}{l}\text { Arsa, Arazi, Yer Üstü } \\
\text { Düzenleri, Yer Altı } \\
\text { Düzenleri, Demirbaş, } \\
\text { Bina, Taşıt, Tesis ve } \\
\text { Makina }\end{array}$ & $\begin{array}{l}\text { Paragraf } 37^{\prime} \text { de çoğu örnek belirtilmekle birlikte } \\
\text { maddi duran varlık kapsamında kabul } \\
\text { edilmektedir. }\end{array}$ & $\begin{array}{l}\text { Maddi duran varlık kapsamında kabul } \\
\text { edilmektedir. }\end{array}$ \\
\hline
\end{tabular}




\section{TÜRKIYE MUHASEBE STANDARTLARI VE VERGI USUL KANUNU'NDA ELDEN ÇIKARILAN MADDI DURAN VARLIKLARIN KARŞILAŞTIRMASI}

Çalışmada elden çıkarılan maddi duran varlıklara ilişkin her iki uygulamaya göre incelemeler ve analizler yapılarak bu incele melere ilişkin olarak karşılaştırmalar yapııımışır.

Tablo 2: Elden Çıkarılan Maddi Duran Varlıkların TMS 16 ve VUK Açısından Karşılaştırması

\begin{tabular}{|c|c|c|}
\hline Karşılaştırma Kıstası & Türkiye Muhasebe Standardı 16 & Vergi Usul Kanunu \\
\hline MDV Tanımlamaları & $\begin{array}{l}\text { Mevcuttur. Bu tanımlar, MSUGT'de yer alan } \\
\text { tanımlar ile de uyumlu olduğu görülmektedir. }\end{array}$ & $\begin{array}{l}\text { Direkt Vergi Usul Kanunu maddelerinde } \\
\text { bulunmamaktadır. Fakat MSUGT'de yer alan tanım } \\
\text { TMS } 16 \text { ile uyumlu olduğu görülmektedir. }\end{array}$ \\
\hline $\begin{array}{l}\text { Maddi Duran Varlıklarin } \\
\text { Siniflandırılması }\end{array}$ & $\begin{array}{l}\text { TMS } 16 \text { paragraf } 37^{\prime} \text { de işletme iştigal konularında } \\
\text { benzer kullanımı olan ve benzer nitelikteki maddi } \\
\text { duran varlıkların MDV sınıfını oluştutacağı } \\
\text { belirtilmekle birlikte ayrı sınıflarda yer alan duran } \\
\text { varlıklardan örneklere yer verilmiştir. Genel } \\
\text { itibarıyla bir sınıflama yer almamaktadır. Örnek } \\
\text { sınıflamalar MSUGT'de yer alan hesap grupları ile } \\
\text { uyumludur. }\end{array}$ & $\begin{array}{l}\text { MSUGT'de sınıflandırma genel hatları itibarıyla hesap } \\
\text { adı bazında yer almaktadır. }\end{array}$ \\
\hline $\begin{array}{l}\text { Arsa, Arazi, Yer Üstü } \\
\text { Düzenleri, Yer Altı } \\
\text { Düzenleri, Demirbaş, } \\
\text { Bina, Taşıt, Tesis ve } \\
\text { Makina }\end{array}$ & $\begin{array}{l}\text { Paragraf } 37 \text { ' de çoğu örnek belirtilmekle birlikte } \\
\text { maddi duran varlık kapsamında kabul edilmektedir. }\end{array}$ & Maddi duran varlık kapsamında kabul edilmektedir. \\
\hline $\begin{array}{l}\text { Maddi Duran Varlığın } \\
\text { Bilanço Dışında } \\
\text { Bırakılması }\end{array}$ & $\begin{array}{l}\text { MDV'nin finansal durum tablosu dışına } \\
\text { çıkarılmasından kaynaklanan kazanç yada kayıp söz } \\
\text { konusu MDV bilançı dışına çıkarıldığında gelir } \\
\text { tablosu hesaplarına intikal ettirilir. Elde edilen } \\
\text { kazanç oluşması durumunda, hasılat niteliğinde } \\
\text { sınıflandırılamaz. }\end{array}$ & $\begin{array}{l}\text { ATiK satışı halinde tahsil edilen bedel ve söz konusu } \\
\text { kıymetin defterde mevcut bulunan değeri arasındaki } \\
\text { fark, eğer satıştan elde edilen bir kar söz konusu ise } \\
\text { kar hesabına ve eğer satıştan zarar oluşuyorsa fark, } \\
\text { zarar hesabına geçirilmesi uygun olacaktır. }\end{array}$ \\
\hline $\begin{array}{l}\text { MDV'nin Satılarak } \\
\text { Bilanço Dışı Bırakılması }\end{array}$ & \multicolumn{2}{|c|}{$\begin{array}{l}\text { Satış nedeniyle oluşan değerle defterde bulunan varlığa ilişkin değer kıyaslanarak satışa ilişkin kar /zarar } \\
\text { hesaplanır. }\end{array}$} \\
\hline $\begin{array}{l}\text { Satıştan Kaynaklanan } \\
\text { Alacak Tutarının Ne } \\
\text { Şekilde Dikkate } \\
\text { Alınacağı }\end{array}$ & $\begin{array}{l}\text { Alacak başlangıçta gerçeğe uygun değer ile kayda } \\
\text { alınır. Daha sonra, içerisindeki vade farkı ve faiz } \\
\text { geliri ayrışııııarak, TMS } 18 \text { gereğince, } \\
\text { gerçekleşme durumuna bağı olarak faiz geliri } \\
\text { şeklinde kaydedilir. }\end{array}$ & $\begin{array}{l}\text { Alacağın tamamı kayıttı değeri ile satış geliri olarak } \\
\text { kayda alınır. Herhangi bir ayrıştırma yapılmaz. }\end{array}$ \\
\hline $\begin{array}{l}\text { Bilanço Dışı Bırakılma } \\
\text { Hallerinin } \\
\text { Düzenlenmesi }\end{array}$ & $\begin{array}{l}\text { MDV'nin satış dışındaki bilanço dışı bırakılması } \\
\text { halleri de belirtilmiştir. }\end{array}$ & $\begin{array}{l}\text { Sadece satış durumunda elden çıkarılma hali var. } \\
\text { Diğer haller uygulamada, tek düzen hesap planı ile } \\
\text { vergideki mevcut uygulamalar doğrultusunda } \\
\text { açıklanabilmektedir. }\end{array}$ \\
\hline $\begin{array}{l}\text { Maddi Duran Varlığın } \\
\text { Bilanço Dışı } \\
\text { Bırakılmasında Elde } \\
\text { Edilen Kar Durumu }\end{array}$ & $\begin{array}{l}\text { Hasılat olarak dikkate alınmaz. Doğan kazanç gelir } \\
\text { tablosu ile ilişkilendirilir. Ve ilgili dönemin kazancı } \\
\text { sayilır. }\end{array}$ & $\begin{array}{l}\text { Hasılat olarak dikkate alınmaz, Doğan kar gelir tablosu } \\
\text { ile ilişkilendirilir. Ve ilgili dönemin kazancı sayılır } \\
\text { Ayrıca, VUK' un 358. maddesine göre karın, gelir } \\
\text { yazılmama seçeneği de mevcuttur. }\end{array}$ \\
\hline Yenileme Fonu & Böyle bir düzenleme mevcut değildir. & $\begin{array}{l}\text { VUK'un 358. maddesine göre karın, gelir yazılmama } \\
\text { seçeneği de mevcuttur. }\end{array}$ \\
\hline $\begin{array}{l}\text { MDV'nin Satılması } \\
\text { Dışında Elden } \\
\text { Çıkarılması }\end{array}$ & $\begin{array}{l}\text { İşletme insiyatifinde bir karar verilerek elden } \\
\text { çıkarma söz konusu olabilir. }\end{array}$ & $\begin{array}{l}\text { Faydalı ömrü doldurmuş ise, bazı durumlarda değeri } \\
\text { serbestçe kayıtlardan düşerek olabilir. Bazı hallerde, } \\
\text { kanunun özel izin ve saptamaları gerekebilir. }\end{array}$ \\
\hline $\begin{array}{l}\text { Gelecekte Yarar } \\
\text { Beklenmeyen MDV'nin } \\
\text { Amortisman } \\
\text { Uygulaması }\end{array}$ & $\begin{array}{l}\text { Sonraki dönemlere varlı̆̆ın ekonomik fayda } \\
\text { sağlayamayacağı öngörülmekte ise ve varlık satış } \\
\text { amaçlı sınıflandırılıyorsa amortisman hesaplama } \\
\text { uygulaması durdurulmaktadır. }\end{array}$ & $\begin{array}{l}\text { Sonraki dönemlere varlığın ekonomik fayda } \\
\text { sağlayamayacağı öngörülmekte ise amortisman } \\
\text { hesaplama uygulaması durdurulmamaktadır. }\end{array}$ \\
\hline Yeniden Değerleme & $\begin{array}{l}\text { Uygulama mevcuttur. } \\
\text { Yeniden değerleme fonu, MDV'nin elden } \\
\text { çıarılması halinde direkt olarak geçmiş yıl karları } \\
\text { hesabına aktarılabilmektedir. }\end{array}$ & Uygulama mevcut değildir. \\
\hline
\end{tabular}




\begin{tabular}{|l|l|l|}
\hline $\begin{array}{l}\text { Finansal Kiralama ile } \\
\text { Elden Çıkarmalar }\end{array}$ & Ayrı bir standart olarak, TMS 17'de düzenlenmiştir. & $\begin{array}{l}\text { Satıştan ayrı olarak VUK'un mükerrer 290'ıncı } \\
\text { maddesinde ayrıca düzenlenmiştir. }\end{array}$ \\
\hline $\begin{array}{l}\text { Satış Amaçlı Elde } \\
\text { Tutulan Maddi Duran } \\
\text { Varlıklar }\end{array}$ & $\begin{array}{l}\text { Amortisman ayrımaya devam edilmez. } \\
\text { MDV dönen varlık kalemlerine aktarılır. } \\
\text { TFRS 5'de düzenlenmiştir. }\end{array}$ & Amortisman ayrılmaya devam edilir. \\
\end{tabular}

\section{ELDEN ÇIKARILAN MADDI DURAN VARLIKLARIN HALKA AÇIK ŞiRKETLERIN FINANSAL TABLOLARINA YANSIMALARIVE ANALIZI}

Konunun daha kolay anlaşılabilmesi açısından bazı halka açık şirketlerin finansal tabloları incelenmiş ve bu finansal tablolara ait dipnotlarda $n$ bazı bölümlere yer verilerek ve elden çıkarılan maddi duran varlıkların finansal tablo ve dipnotlarına yansımaları değerlendirilmiştir .

İşletmelerin elden çıkardıkları maddi duran varlıklara ilişkin bilgiler KAP üzerinden elde edilmiştir. Finansal tablo dipnotlarından, elden çıkarılan maddi duran varlıklara ilişkin incelemeler yapılmıştır. Bu şirketlere ilişkin bazı finansal tablolara ait bilgiler ve tablolara ilişkin dipnotlara ve değerlendirmelere çalışmanın devamında yer verilmiştir.

Bazı halka açık firmaların finansal tablo ve finansal tablo dipnotları incelemeleri doğrultusunda maddi duran varlık standardı çerçevesinde elden çıkarılan maddi duran varlıkların finansal tablolara yansımalarına ilişkin analizler aşağıda yer verilen tablo ile açık lanmaya çalışılmıştır.

Tablo 3: İncelenen Firmalarda Elden Çıkardıkları Maddi Duran Varlıkların Finansal Tablolara Yansımaları

\begin{tabular}{|c|c|}
\hline Firmalar & $\begin{array}{l}\text { Türkiye Muhasebe Standartlarına Göre Hazırlanan Finansal Tablo ve Dipnotlarda } \\
\text { Bulunan Elden Çıkarılan Maddi Duran Varlıklara İlişkin Analiz }\end{array}$ \\
\hline $\begin{array}{l}\text { Pegasus Hava Taş. A.Ş. ve Bağlı } \\
\text { Ortaklıkları }\end{array}$ & $\begin{array}{l}\text { Grubun } 2018 \text { hesap döneminde uçak satışı nedeniyle meydana gelen kayıp ya da kazancı, } \\
\text { varlığa ait defterde kayıtlı değerle satım dolayısıyla elde edilen hasılat arasında oluşan } \\
\text { fark tutarı şeklinde belirleyerek dönem sonunda kar zarar tablosuna dahil ettiği } \\
\text { anlaşılımaktadır. }\end{array}$ \\
\hline Sasa Polyester San. A.Ş. ve Bağı Ortaklığı & $\begin{array}{l}\text { Grupta atıl durumda bulunan muhtelif makine ve ekipman satışı neticesinde 01.01.2019- } \\
\text { 30.09.2019 döneminde oluşan kazanç veya kayıbı varlığa ait defterde kayıtlı değerle satım } \\
\text { dolayısıyla elde edilen hasılat arasında oluşan fark tutarı şeklinde belirleyerek 30.09.2019 } \\
\text { tarihli kar veya zarar tablosuna dahil ettiği anlaşılmaktadır. }\end{array}$ \\
\hline Mondi Tire Kutsan Kağıt ve Amb. San. A.Ş. & $\begin{array}{l}2018 \text { hesap döneminde bulunan bazı tesis, makine ve teçhizatlar, taşıt araçları, demirbaş } \\
\text { ve döşemeler bilanço dışı bırakılmıştır. MDV'nin bilanço dışı bırakılması neticesinde elde } \\
\text { edilmiş olan kar ya da zararı, söz konusu MDV'nin taşıdığı değere göre belirlediği ve } \\
\text { oluşan karı yatırım faaliyetlerinden gelirler hesabında, oluşan zararı ise yatırım } \\
\text { faaliyetlerinden giderler hesabında raporladığı anlaşılmaktadır. }\end{array}$ \\
\hline Desa DeriSan. ve Tic. A.Ş. & $\begin{array}{l}2018 \text { hesap döneminde aktifinde bulunan bazı makine, tesisleri, ve demir başları bilanço } \\
\text { dışı bırakılmıştır. maddi duran varlıkların elden çıkarılması sonucu oluşan karı, düzeltilen } \\
\text { tutarlarla tahsil edilen tutarların karşılaştırılmasıyla belirleyip cari dönemde yatırım } \\
\text { faaliyetlerinden gelirler hesabında raporladığı anlaşılmaktadır. }\end{array}$ \\
\hline $\begin{array}{l}\text { Bak Ambalaj San. ve Tic. A.Ş. ve Bağlı } \\
\text { Ortaklıkları }\end{array}$ & $\begin{array}{l}\text { Grubun } 2017 \text { hesap döneminde makine ve tesis, taşıt araçları, döşeme ve demirbaşlarının } \\
\text { elden çıkarılması sonucu oluşan karı, tahsil edilen tutarla düzeltilen tutar karşılaştırması } \\
\text { yaparak belirleyip cari dönemde yatırım faaliyetinden gelir olarak gelir tablosunda } \\
\text { raporladığı anlaşılmaktadır. }\end{array}$ \\
\hline
\end{tabular}

\section{SONUÇ VEÖNERILER}

Çalışmanın bütünlüğü ayrıntılı incelendiğinde VUK'ta yer alan yenileme fonu uygulamasının TMS 16 ' da yer almaması, TMS 16 uyarınca madd duran varlığın sonraki dönemlerde iktisadi fayda sağlaması umulmaması dolayısıyla amortisman hesaplanmamasının mümkün olduğu fakat VUK uygulamalarında amortisman ayrılmaya devam edildiği, maddi duran varlığın satışından elde edilen alacak başlangıçta gerçeğe uygun değer ile kayda alınacağı daha sonrasında, içerisindeki vade farkı ve faiz geliri ayrıştırılarak, TMS 18 gereğince, gerçekl eşme durumuna bağ olarak faiz geliri şeklinde kaydedileceği fakat VUK'ta elde edilen hasılatın diğer olağan dışı kar olarak gelir tablosu hesabında sınıflanacağı farklılıkları dikkat çekmektedir.

Maddi duran varlığın elden çıkarılmasında özellikle yenileme fonu uygulaması, yeniden değerleme fonu uygulaması, sonraki dönemlerde varlığın ekonomik fayda sağlayamayacağı öngörülen maddi duran varlıklarda amortisman uygulamaları ve MDV'nin satışı dışında e lden çıkarılması konularında her iki mevzuat birbirinden ayrılmaktadır.

İncelenen firmaların elden çıkarılan maddi duran varlıklarını TMS kapsamında hazırladıkları kapsamlı gelir tablosunda TMS 16 hükümleri gereğince elden çıkarılmaları sırasında elde edilen karı yatırım faaliyetlerinden gelirler, elden çıkarılmalarından kaynaklanan zararı ise yatırım faaliyetlerinden giderler bölümlerinde raporladıkları anlaşılmıştır. VUK'a göre hazırlanan gelir tablosunda bu tutarlar Diğer Faaliyetlerden Olağan Gelir ve Karlar ya da Diğer Faaliyetlerden Olağan Gider ve Zararlar bölümünde gösterilecektir.

Her iki mevzuata göre oluşturulan mali tablolarda elden çıkarılan maddi duran varlıklara ilişkin kar/zarar durumu farklı uygulamalar dolayısıla birbirinden farklı olarak oluşacaktır.

Farkılılıklar ortaya konduğundan bu farklılıkları en aza indirmek doğru finansal tablo sonuçları oluşmasında yararlı olacaktır. 


\section{KAYNAKÇA}

Akgül, B. ve Akay, H. (2003) “Uluslararası Muhasebe Standartları ve Türkiye'de Uygulama Etkinliğine iliş̧in Bir Araştırma” 2. Baskı, İstanbul, Türkmen Kitabevi, s.4-5.

Fahran, F. (2016) Vergi Usul Kanunu Muhasebe Uygulamaları ve TFRS/TMS Karşılaştırmaları, Ankara, Yaklaşım Yayıncılık.

Gençoğlu, Ü. G. ve Diğerleri. (2013). Genel Muhasebe II, 2.Baskı, Eskişehir, Anadolu Üniversitesi Yayını No:2897 -Açı̈öğretim Fakültesi Yayını No:1854. ss. 41.

Demir, Ş. (2014). Türkiye Muhasebe Ve Finansal Raporlama Standartları, İstanbul, Seçkin Yayıncılık, ss. 64-224.

Kıymetli Şen, I., (2013). Maddi Duran Varlıklar (TMS 16) Standardının Üretim İşletmelerinde Satışların Maliyetine Ektileri, Çankırı Karatekin Üniversitesi I.i. B.F. Dergisi, 3 (1), ss. 21-36.

Sevilengül, O. (2013). Genel Muhasebe, Ankara, Gazi Kitabevi, ss.433.

Tekşen, Ö. Dağlı, S. (2017). "Maddi Duran Varlıkların Tekdüzen Muhasebe Sistemi İle Vergi Usul Kanunu ve TMS-16 Açısından İncelenmesi: Bir Uygulama", Mehmet Akif Ersoy Üniversitesi Sosyal Bilimler Enstitüsü Dergisi, Eylül 2017, Sayı:20, ss.424-447.

Yazııı, M. (2003). Muhasebe Standardının Tanımı, Muhasebe ve Finansman Dergisi, Sayı: 18, s. 35. 